\title{
Empowerment of Women in India: A Critical Analysis
}

\author{
Dr. B. Nagaraja, M.A. Ph.D \\ Associate Professor Department of Economics Sri Venkateswara University College of Arts Sri Venkateswara \\ University TIRUPATI
}

\begin{abstract}
The present paper primarily deals with "empowerment of women" in India and throws light on particularly" agency approach"to measure women empowerment. Divided into three sections, this paper presents the illustration of modern approach to empowerment in Section-I; an overview of the efforts put in India for empowering women in Section-II and analyses the degree of achievement of empowerment by adopting some of the modern indicators in Section-III. This paper hinges fundamentally on secondary sources of data related to India, published by National Family Health Survey, National Sample Survey Organization and some of the research papers.
\end{abstract}

Key words: Empowerment, Agency, Gender Gap, Access to Resources, Control over Resources, Economic participation and opportunity.

\section{Introduction:}

The concept of "empowerment" traces its history in the mid- $17^{\text {th }}$ century with the legalistic meaning "to invest with authority". Thereafter, this concept was modernized to mean "to enable or permit". After 1980's, the novel concept of measuring economic development through "human development" focusing on "political empowerment" linkage with feminist discourse went a long way in shaping the idea of "women's empowerment" . During 1990's economists agued that "development if not engendered, is endangered" and the major component of the global society i.e. women are left outside the purview of the fruits of development and planning, we cannot achieve the desired goal of a "developed status" of an economy, whether it is developed or developing . The United Nations has shown concern for women empowerment evident in "Millennium Development Goals" to trace the progress of women empowerment across the world.

\section{SECTION - I \\ APPROACHES TO EMPOWERMENT}

We know well that in general terms, the position of women in society is still low compared to their counterparts. Particularly in developing countries women have to face "the glass ceiling". The major reason being the discrimination between man and woman on the basis of sex has created various types of gender biases. Hence, efforts were made to remove discrimination against females and to establish equality has become the part of the global movement emphasized in all the four World Conferences on Women including the Beijing Conference in 1995.

The World Bank has identified empowerment as one of the key constituent elements of poverty reduction and as a primary development assistance goal. The promotion of women's empowerment as a development goal is based on the dual argument that social justice is an important aspect of human welfare. The Policy Research Report of the World Bank has also identified gender equality both as a development objective and as a means to promote growth, reduce poverty and promote better governance. Beijing Declaration (1995) presented women's empowerment as a key strategy for development and stated that "women's full participation on the basis of equality in all spheres of society, including participation in the decision making process and access to power are fundamental for the achievement of equality, development and peace.

Another line of thought in development literature has promoted 'social inclusion' in the institutions as the key pathway to empowerment of individuals and capitalism top-down approaches to development and /or poverty itself are seen as sources of disempowerment. This process of social inclusion was viewed as a process that removes the institutional barriers and the enhancement of incentives to increase the access of diverse individuals and groups to assets and development opportunities (Beteta Hanny,2006). The growth of civil society and participatory development methods at both macro and micro levels of society were also proposed as the mechanisms by which empowerment could take place. This approach to empowerment focuses on State and Civil Society institutions and interpersonal gender dynamics within the household as a part of the equation of social exclusion and in need of directed efforts at change. 


\section{The Modern Approach:}

In recent years the concept of "empowerment" was modified to include "the power in plural form as "powers". This "powers" approach was picked up by several feminist bodies and development NGOs which have argued that empowerment process should be broken down in four levels of power - power over, power to, power with and power within. A revised definition of poverty during the reforms period brought out a new dimension of empowerment. Haschemi and Schuler (1993) have identified six dimensions of empowerment based on activities of women identified as important for their day-to-day functioning. The concept "Poverty" was also redefined as "lack of real opportunity" and ultimately a matter of "capability deprivation". Hence, it was argued that the basic objective of development was the "expansion of human capabilities" (Jean Dreze and Amartyasen, 1995). It was also argued that expansion of human capabilities empowers the people and facilitates the reduction of social and economic inequalities. Attempts were made to separate the gender and economic components of empowerment by combining the models of empowerment proposed by Kabeer (1999) and England (2000)/ Kabeer (1999) identified three main elements of empowerment: The first one is the preconditions of empowerment which include economic as well as human and social resources. The second one is "achievements". Gender norms and economic resources must act as preconditions to exercise the power that positively affects the demographic outcomes. (Social Opportunities) and also to have an independent influence on these "achievements". Malhotra et.al.(2002) used the definition of empowerment suggested by Kabeer (1999) and argued that empowerment is "the expansion of people's ability to make strategic life choices in a context where this ability was previously denied to them". To be precise, it could said that to be "empowered" means "to exercise more power than other women in the same context". Based on these arguments, efforts were made to build models that separate the gender and economic components of empowerment proposed by Kabeer (1999) and England (2000) as shown in fig. 1.

Fig.1: Conceptual Model of Gender and Women Empowerment

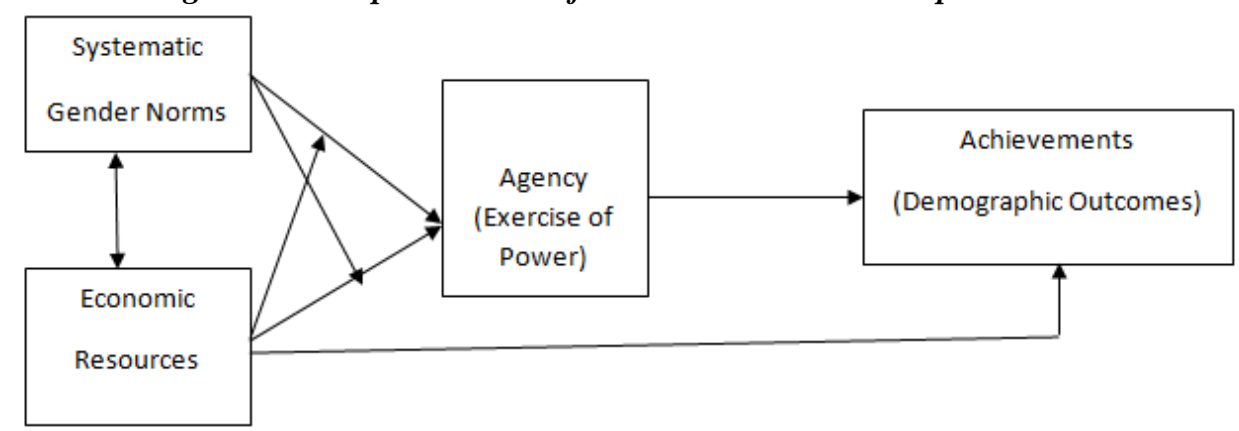

Source: Jill Williams (2005) Measuring Gender and Women's Empowerment Using

Confirmatory Factor Analysis, IBS Working Paper, PAC- 2005-01.

Of late, the Human Development Reports have been emphasizing on thinking about equality in terms of capabilities because inequalities in outcomes are largely the product of unequal access to capabilities. The Human Development Reports have introduced "Gender Related Development Index (GDI) (to measure average achievements in long and healthy life, knowledge and a decent standard of living which account for inequalities between men and women), Gender Empowerment Measure (GEM) (which measures gender inequality) and Gender Inequality Index (GII- Human Development Report-2010)(which measures the losses due to gender inequalities in reproductive health, empowerment and labour market participation). The Human Development Report -2010 observed that human development is a participatory and dynamic process and people are the real wealth of a nation and the process has three important components viz., well-being, empowerment and agency and justice (equality). Particularly it was stressed that empowerment requires both agency and supportive institutional structures and empowerment is about people as individuals and acting in groups. The World Development Report-2012 observed that greater gender equality enhances productivity, improves development outcomes for the next generation and make institutions more representative. The United Nation Population Fund (2003) believed that "gender inequality holds back economic growth of individuals, development of countries and the evolution of societies and economic growth and social equality should go hand in hand. The World Economic Forum has been publishing The Global Gender Gap reports since 2006 and its Report- 2012 focused on three basic concepts underlying the Global Gender Gap Index. First, it focused on measuring the gaps between men and women rather than on levels. Second, it captured gaps in outcome variables rather than on gaps in means or input variables. Third, it ranked countries according to gender equality rather than women empowerment. 


\section{SECTION - II \\ Empowerment of Women in India}

According to Census-2011, India has reached the population of 1210 million, as against 301 million in 1951 , of which 58,64,69,174 (48.5\%) were females. The population of India accounted for $17.5 \%$ of the total world population and occupied second place. The sex ratio was 930 in 1971 and it has increased to 940 according to 2011 Census. The female literacy also increased from $18.3 \%$ in 1961 to $74.0 \%$ in 2011 and a decrease in male-female literacy gap from $26.6 \%$ in 1981 to 16.7 per cent in 2011.

Women empowerment in India is heavily dependent on many different variables that include geographical location (rural/urban), educational status, social status (caste and class) and age. Policies on women empowerment exist at national, state and local levels in many sectors including health, education, economic opportunities, gender based violence and political participation. The scope and coverage of the schemes launched has been expanding that include initiatives for economic and social empowerment of women and for securing gender equality. The following schemes at present are aiming at women empowerment and gender equality in India:

1. Integrated Child Development Services (ICDS) (1975)

2. Rajiv Gandhi Scheme for Empowerment of Adolescent Girls (RGSEAG) (2010)

3. The Rajiv Gandhi National Crèche Scheme for Children of Working Mothers.

4. Integrated Child Protection Scheme (ICPS) (2009-10)

5. Support to Training and Employment Programme for Women (STEP)

6. Dhanalakshmi (2008)

7. Short Stay Homes

8. Swadhar

9. Ujjawala (2007)

10. Scheme for Gender Budgeting (XI Plan)

11. National Mission for Empowerment of Women

12. Rashtriya Mahila Kosh (1993)

In spite of the effective implementation of all the above schemes and progrmmes, there are significant gaps between policy achievements and actual practice at the community level. The Global Gender Gap Index (2012) observed that India is simply not doing enough for its women. The ranking of the country has fallen from 113 (out of 134 countries) in 2010 to 113 and out of 135 countries in 2011. However, in 2012, its ranking has improved from 113 in 2011 to 105 with a score of 0.644 in 2012 according to the recent report of the World Economic Forum. The World Report-2012 released by the Human Rights Watch (Events of 2011) also observed that social unrest and protests deepened in resource rich areas of central and eastern India, where rapid economic growth was accompanied by rapidly growing inequality. Despite repeated claims of progress by the Government, there was no significant improvement in access to health care and education. According to the latest statistics released by World Economic Forum(2012) indicate that the current situation of gender gaps is alarming and India ranks after our neighbor country Sri lanka in all sub-indices except in political empowerment as shown in Table.1.

Table. 1. Details of Gender Gap Index -2012 (Out of 135 Countries)

\begin{tabular}{|c|c|c|c|c|}
\hline \multirow[b]{2}{*}{ Gender Gap sub-Indices } & \multicolumn{2}{|c|}{ India } & \multicolumn{2}{|c|}{ Sri Lanka } \\
\hline & Rank & Score & Rank & Score \\
\hline $\begin{array}{lll}\text { 1.Economic } & \text { Participation } & \text { and } \\
\text { Opportunity } & \end{array}$ & 123 & 0.4588 & 105 & 0.5596 \\
\hline 2. Educational Atainment & 121 & 0.8525 & 108 & 09946 \\
\hline 3.Health and Survival & 134 & 0.9612 & 1 & 09796 \\
\hline 4. Political Empowerment & 17 & 0.3343 & 22 & 03151 \\
\hline Overall Index & 105 & 0.6442 & 39 & 0.7122 \\
\hline
\end{tabular}

Source: World Economic Forum (2012) Global Gender gap Index -2012, p.10-11.

The rankings and scores for India amply proves that it is found in the lower rank even compared to Sri Lanka in all sub-indexes of gender equality. India gained eight places (from 113 rank in 2011 to 105 rank in 2012) as a result of improvements in the educational attainments and political empowerment. Among the BRIC economies, India is the lowest ranked featured in the index. The report has observed that the persistent health, education and economic participation gaps are acting as detrimental forces to India's growth. The disproportionate sex ratio at birth has not changed over the past years.(WEF,2012). 


\section{SECTION -III \\ EVALUATION OF EMPOWERMENT}

Not only Global reports have observed the above inequalities but the national level reports have also identified that India has to go a long way to achieve 'agency' for women and empower them socially and economically. Keeping the status of women empowerment and its determinants in India, in this paper an attempt is made to present some of the key determinants of inequalities that exist in our country so as to have an idea about to what extent the women are empowered?

\section{Educational Attainments:}

No doubt, India has attained significant improvement in women's literacy which was $8.9 \%$ in 1951 , improved to $65.5 \%$ as on 2011. As a result the male-female gap in literacy has narrowed down from $26.6 \%$ in 1981 to $16.7 \%$ in 2011. However, the Human Development Report-2011 observed that the population with at least secondary education (\% age 25 and above) was only $26.6 \%$ for females as against $50.4 \%$ for males.(Human Development Report-2011). Net Attendance Ratio at primary and upper primary levels in rural areas and in urban areas was found for females were completely low during 2007-08 (India Human Development Report-2011). Net Attendance Ratio at higher secondary level for females was only $20.0 \%$ in rural areas and $39.0 \%$ in urban areas. Inspite of the implementation of programmes like 'Sarva Siksha Abhiyan', still $21.8 \%$ of the girl children (6-17 years age) were found out of schools.

Although the gender differential in literacy has declined over time, the differential remains high even in the youngest age group among those 15-19 years of age, the percentage of females who are literate $(74 \%)$ is $15 \%$, which is less than the males (89\%). The National Family Health Survery-3 (2009) observed that there are great disparities in literacy by wealth especially for women.

\section{Economic Participation and Opportunity:}

Women's participation in labour force is seen as a signal of declining discrimination and increasing empowerment of women. It is thought that feminization of the workforce is also a sign of improvement of women's opportunities and position in society. In India, the statistics show that in both rural and urban areas, the Labour force Participation Rate had declined in 2009-10 as compared to 1003-94 particularly for females as shown in Table. 2.

Table.2. Labour force Participation of Females and Males in India by Usual Principal and Subsidiary Status (Percentage) (for Population aged 15 years and above)

\begin{tabular}{|c|c|c|c|c|c|c|}
\hline \multirow{3}{*}{ Sector } & \multicolumn{2}{|c|}{ Males } & \multicolumn{2}{c|}{ Females } & \multicolumn{2}{c|}{ Persons } \\
\cline { 2 - 7 } & $1993-$ & $2009-$ & $1993-$ & $2009-$ & $1993-$ & $2009-$ \\
& 94 & 10 & 94 & 10 & 94 & 10 \\
\hline Rural & 87.6 & 82.5 & 49.0 & 37.8 & 68.6 & 60.4 \\
\hline Urban & 80.1 & 76.2 & 23.8 & 19.4 & 53.3 & 48.8 \\
\hline
\end{tabular}

Source: NSS Reports No.409 and 515

The data in Table. 2 amply reveal the fact that in India there are considerable gender disparities in Labour force Participation Rates. The female labour force participation rate has declined from $49.0 \%$ to $37.8 \%$ and from $23.8 \%$ to $19.4 \%$ in rural and urban areas respectively between 1993-94 and 2009-10. The second conclusion is that in 2009-1-, the female labour force participation rate is only $19.4 \%$ as against $76.2 \%$ for males.

The low labour force participation rates may be due to the reason that women's work is statistically less visible, non-monetized and relegated to subsistence production and domestic side and estimation reveal that this proportion accounts for $60.0 \%$ of unpaid work and $98 \%$ of domestic work. The India Human Development Report-201 observed that poor access to education was one of the reasons for higher labour force participation rate in rural areas particularly for females. Further, there is huge gender disparity in both rural and urban areas for females with reference to Worker Population Ratio. Women's workforce participation rate was almost half of that of men in rural areas and less than a third in urban areas. These figures make it clear that the achievement of economic development for the past 60 years did not had a telling effect on Workforce Participation Rate for females in India as almost no change took place in this vital index of women empowerment.

\section{Women and Employment:}

Employment can also be an important source of empowerment for women, particularly for cash and in the formal sector. Employment empowers women by providing financial independence, alternative source of social identity and exposure to power structures. Data on women's and men's employment is presented in Table. 3 to bring about the gender differential in employment. 
Table. 3. Percentage of Women and Men age 15-49 Employment for the Period of 12 Months

\begin{tabular}{|c|c|c|}
\hline \multirow{2}{*}{$\begin{array}{c}\text { By Residence } \\
\text { and Age }\end{array}$} & \multicolumn{2}{|c|}{ All India } \\
\cline { 2 - 3 } 1. Residence: & & Men \\
\hline Urban & 29.3 & 84.0 \\
\hline Rural & 49.4 & 88.7 \\
\hline Age: & & 50.4 \\
\hline $15-19$ & 33.4 & 90.3 \\
\hline $20-29$ & 38.5 & 99.0 \\
\hline $30-39$ & 50.6 & 98.5 \\
\hline $40-49$ & 49.7 & \\
\hline
\end{tabular}

Source: Sunitha Kishor and Kamla Gupta (2009) Gender Equity and Women's Empowerment in India

The data in Table. 3 reveal that women's employment both in rural and urban areas is very low compared with men, particularly in urban areas. It is also found that $49.4 \%$ of the women are employed in rural areas (as against $88.7 \%$ of males) as the agricultural work is typically more compatible with women's responsibilities as well as with low education. Employment by age also exhibits a serious gender gap. Employment is found at peak in al the age groups for men, whereas for women it is found at peak in the age group of 30-39 years (also for males). In each and every age group, the percentage of women employment is low compared to that of men in our country.

\section{Access to Resources:}

Access to resources is important for economic freedom of women as freedom of movement is linked with their economic independence and also infuses with power and expands agency. The National Family Health Survey-3 has identified five important variables namely: knowledge of loan progrmme, get loan, having bank account, higher educational attainment and working outside as a measure of economic independence. NFHS-3 has also captured "exposure to media" through four variables namely: reading newspaper every day, listening radio every day, watching TV every day and knowing about modern contraceptives, as the measurement indicators of women's empowerment. The media is important source of information and exposure to new ways of thinking and doing things. Besides, radio listening, TV watching and reading news papers or magazines are important leisure activities and represent an important indication of women's empowerment and have the potential for enabling environment by facilitating greater control over their own time use. The summary of results of all these variables observed is presented in Table. 4.

Table. 4.Women's Access to Resources and Exposure to Mass Media

\begin{tabular}{|l|l|r|l|}
\hline \multicolumn{1}{|c|}{ Variables of Empowerment } & \% of Women & Index \\
\hline & Access to Resources: & & \\
\hline & a) Know about Loan Programme & 38.6 & \\
\hline & b) Given Loan & 10.48 & \\
\hline & c) Having Bank Saving Account & 15.07 & \\
\hline & d) Educational Attainment-- Higher & 7.3 & \\
\hline & Exposure to Mass Media & 36.35 & \\
\hline I & Rreedom of Working Outside & 12.54 & \\
\hline & a) Read Newspapers Everyday & 17.14 & \\
\hline & c) Wasten Radio Everyday & 43.66 & \\
\hline & d) Knows about Modern Contraceptives & 97.95 & \\
\hline & & & 0.7259 \\
\hline
\end{tabular}

\section{Source: NFHS-3}

It is evident from the data in Table. 4 that women's access to resources is dismally poor in our country. The data show that only $22.0 \%$ of women have access to resources in general and at disaggregate level it is seen that a meager $38.6 \%$ of women know about the loan programmes and only $10.5 \%$ of women could get a loan. It is quite disappointing to note that the women who have a bank saving account was found very low at $15.07 \%$ and in spite of knowing about loan programmes, they have failed to secure a loan. $36.4 \%$ of the women had the freedom to work in outside. These variables are closely associated with level of education and the higher education, a potent source of empowerment was found at only $7.3 \%$ for women. 
It is also evident that women have least exposure to mass media and almost all women know (98\%) about modern contraceptives. The percentage of women who read news papers and listen to raid every day was estimated at $12.5 \%$ and $17.1 \%$ only. It is evident that in our country only $43.7 \%$ of women are watching TV everyday. It means $87 \%, 83 \%$ and $56 \%$ of the women in our country are not reading news papers, listening to radio and watching TV everyday respectively. However, about the modern contraceptives had a great bearing on the estimation of index for access to resources at 0.7259. NFHS-3 shows that women are less likely than men to have at least weekly exposure to TV (55\% Vs. 63\%). Radio (29\% Vs 44\%), newspaper and magazines $(23 \%$ Vs. $53 \%)$. In total, $35 \%$ of women have no regular exposure to these forms of media compared with $18 \%$ of men. The details on gender-differential in media show that it is greater for younger than older age groups.

\section{Freedom of Movement:}

Freedom of movement, no doubt, is an important indicator for measuring empowerment of women particularly to the places outside the home and community. However, particularly in India, movement of women is seriously curtailed for larger portion of women due to a variety of social, religious and economic reasons. The experts feel that even marriage has a significant impact on movement of women outside the home. The details of access to spaces outside the home according to the NFHS-3 are presented in Table. 5.

Table 5. Percentage of Women (age 15-49) who have Access to Spaces Outside the Home

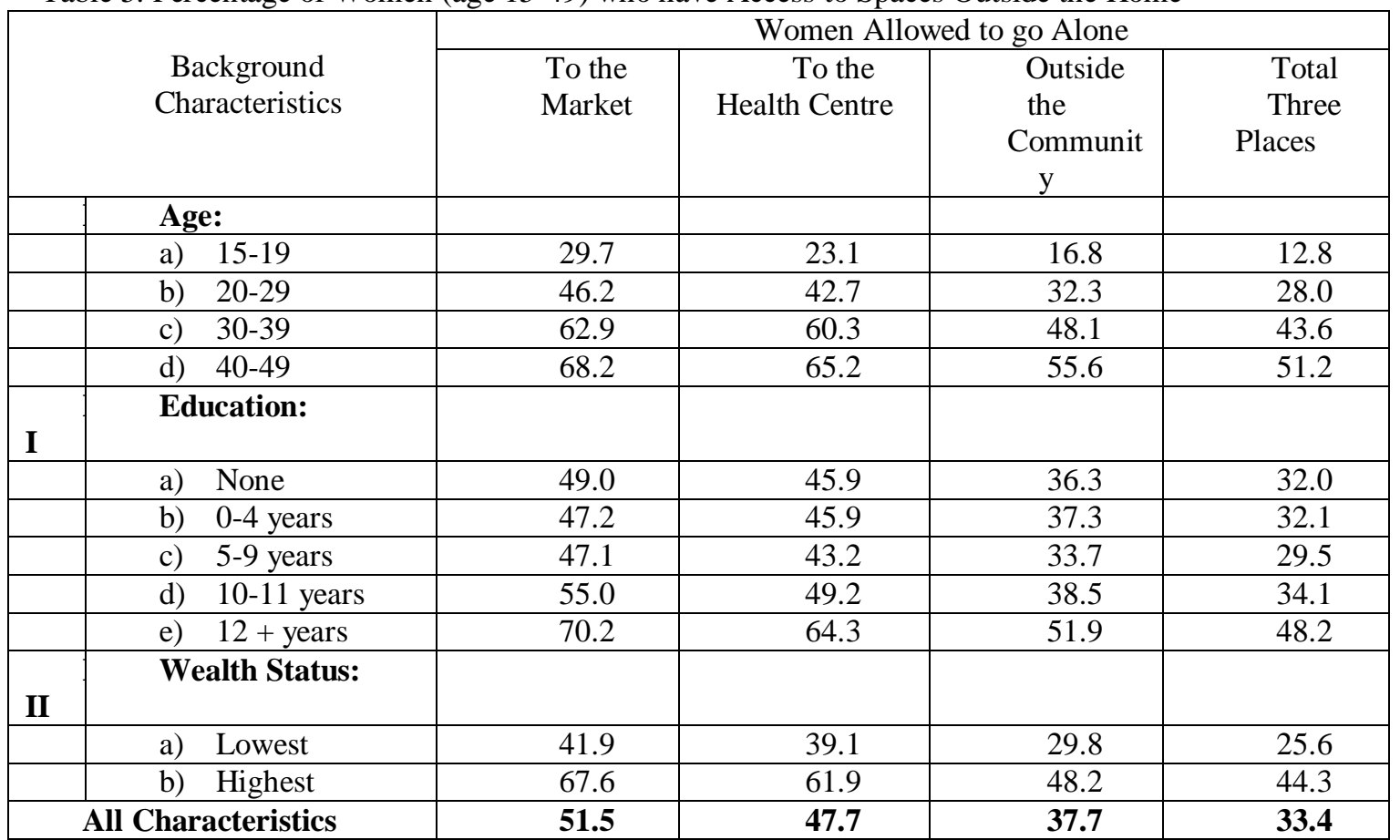

Source: NFHS-3, p. 63.

It is quite evident from the data in Table. 5 that only one third of women age 15-49 are allowed to go alone to outside the home in general. In particular the data reveal that as age of women increases, the percentage of women allowed to go alone to the three places also increases $48 \%, 52 \%$ and $62 \%$ of women could not go alone to the market, to the health centre and outside the community respectively.

Similarly, if we look at the correlation between the education, wealth and access to spaces outside the home increases with both education and wealth. The data reveals that only $32 \%$ of women without education were allowed to go alone to all the three places and it varies to $48.2 \%$ with more than 12 years of education. The overall percentage of women, who could not go alone to these three places, was estimated was high at $52 \%$. A similar trend is found with the correlation between status of wealth and the access to spaces outside the home, $74 \%$ of the women, who belong to lowest quintile of wealth and $56 \%$ of women with highest wealth status could not go alone to all these three places. It seems in India, even educated and women with high wealth status, are not having the opportunity to go alone outside the home due to a variety of social, cultural and other reasons.

\section{Control Over Own Earnings:}

"Empowerment" also means "to invest with power". In the context of women empowerment, it refers to increased control over their own lives, bodies and environment. Hence, an important indicator of "agency" is decision making power. For women particularly the post-marriage phase of life decides the capability of 
women to overcome barriers all translate into increased/decreased agency. The data in Table. 6 examine the control women and men have over their own earnings.

Table. 6. Percentage of Currently Married Women and Men (age 15-49) Employed for Cash and the Use of Own Earnings.

\begin{tabular}{|c|c|c|c|c|c|}
\hline \multicolumn{2}{|c}{$\begin{array}{c}\text { of women with earnings who make } \\
\text { decisions about use of earnings. }\end{array}$} & \multicolumn{2}{c}{$\begin{array}{c}\text { of men with earnings who make } \\
\text { decisions about use of earnings. }\end{array}$} \\
\hline Alone & Jointly & $\begin{array}{c}\text { Alone or } \\
\text { Jointly }\end{array}$ & $\begin{array}{c}\text { Alon } \\
\text { e }\end{array}$ & Jointly & Alone or Jointly \\
\hline 24.4 & 56.5 & 80.9 & 28.1 & 66.1 & 94.2 \\
\hline
\end{tabular}

Source: NFHS-3, p. 85

The data in Table. 6 on use of own earnings indicate that there are notable gender differences in control over own earnings. Married men are more likely than married women to be involved in decisions about the use of their own earnings. The data also show that men have higher level of decision making power $(28.1 \%)$ compared to women (24.4\%) to use their own earnings. Further, it is evident that $76 \%$ of women are unable to make decisions alone about the use of their own earnings.

\section{Participation in Household Decisions:}

NFHS-3 has collected data on how women are participating in several other decisions and who usually makes them. Specifically, decisions related to own health care, large household purchases and visits to family or relations are considered for analysis and the gender differential is presented in Table.7.

Table. 7. Percentage of Currently Married Women age 15-49 who usually make Specific Decisions alone or jointly

\begin{tabular}{|c|c|c|}
\hline \multirow[b]{2}{*}{ Type of Decision } & \multicolumn{2}{|c|}{ Make Decisions } \\
\hline & Alone & Jointly \\
\hline 1. Own Health Care & 27.1 & 35.1 \\
\hline 2. $\quad$ Large Household Purchases & 8.5 & 44.4 \\
\hline 3. Visits to Her Family or Relations & 10.7 & 49.8 \\
\hline All decisions & 15.4 & 43.1 \\
\hline
\end{tabular}

Source: NFHS-3, p. 89.

The data on specific decisions and how they are being taken by the women exhibit that $73 \%, 91 \%$ and $89 \%$ of women even today are not able to take decisions alone with respect to their own health care, large household purchases and could not decide themselves even to visit their family or relatives respectively. Less than $50 \%$ of women have participated in decisions about visits to their family or relations jointly and only $35.1 \%$ of women have participated in decisions about their own health care jointly..

The data on the net determinants of participation in decision making collected by NFHS-3 and the results of ordinary least squares regressions run for the survey revealed that the percentage of women making no decisions alone accounted for $53 \%$ and the percentage making all decisions alone was only $2 \%$

\section{Spousal Violence:}

Domestic violence is one of the most common forms of gender-based violence experienced by women across the world. Domestic violence results into violation of human rights and economic costs. It leads to both short term and long term detrimental effects on the health and welfare of women and their children. Living with constant threat of domestic violence is, as considered by experts, acts as a source of disempowerment of women. Domestic violence takes the forms like emotional, physical and sexual violence by their husbands.

It was observed that $27 \%$ of currently married women age 15-49 have experienced the violence during a survey period of 12 months according to NFHS-3. 55\% of women who have experienced physical and sexual violence reported that they were injured by their husbands. Cuts, eye injuries, sprains, dislocations, deep wounds, broken bones, broken teeth and other serious injuries were the types of injuries reported.

\section{Autonomy of Women:}

Autonomy of women in control over decision making freedom in sexual relations, freedom of movement and women's attitude towards wife-beating are considered as indicators of women empowerment by the experts. Autonomy of women in refusing sexual intercourse with their husbands is a very forceful expression of women's control over their sexuality and control over one's sexual life is integral to women's well-being and autonomy. The details of freedom in sexual relations and the women's attitude towards wife beating, collected by NFHS-3 is presented in Table. 8 


\begin{tabular}{|l|l|c|}
\hline \multicolumn{1}{|c|}{ Variables of Autonomy } & \% of women Reported \\
\hline & Freedom in Sexual Relations: & 77.85 \\
\hline & 1. Can say no to have sex if husband has STD & 79.30 \\
\hline & 2. Can say no to have sex if husband has another women & 77.39 \\
\hline I & Women's Attitude Toward Wife-Beating: & 69.85 \\
\hline & 1.Wife beating is justified if she goes without telling husband - said No & 64.21 \\
\hline & 2.Wife beating is justified if she neglects children - said No & 68.08 \\
\hline & 3.Wife beating justified if she argues with husband - said No & 81.71 \\
\hline & 4.Wife beating is justified if she refuses to have sex - said No & 78.40 \\
\hline & 5. Wife beating is justified if she burns the food - said No & \\
\hline
\end{tabular}

Source: NFHS-3, pp. 103-110.

The data presented in Table 8 on female autonomy deals with two important determinants of autonomy of women as indicators of empowerment. The data reveal that more than $78 \%$ of women in India had hold on sexual intercourse with their husband. It is evident that in all the three types of reproductive freedoms percentage of women is almost identical $(77.9 \%, 79.3 \%$, and $77.4 \%)$. The overall index was worked out as 0.9761 , which show highest degree of autonomy.

Wife beating is found in India as one of many types of domestic violence on women. It is observed that it is fairly accepted by the women themselves. Wife beating was justified by the women to the extent of more than $64 \%$ of women were found must assertive in rejecting the wife beating as the overall index worked out to 0.9599 .

\section{Conclusion:}

The forgoing discussion amply reveals that though the concepts -empowerment, agency and autonomy have been used interchangeably, in practice it is found that they can substantially diverge from each other and are may not reflect into the other. This divergence tells us that there is a need for identification of some cultural factors having bearing on empowerment and autonomy. There is a need to understand that the concepts of empowerment and autonomy are sufficiently different. As the data presented in the above tables exhibited, still a large part of women do not have sufficient autonomy regarding the value choices for their own life. The data also makes us to infer that there is a necessity to look beyond economic resources or material prosperity and into cultural and social influences, which are playing a significant role in shaping the women's autonomy and agency. Again, it is also true that though not the women's empowerment and autonomy have a link with women's access to resources or material well-being, it is to be accepted that there is a variety of potential connections and there exists various forms of linkages among these variables. Hence, the answer for the question "Are women really empowered in India" is nothing but "not yet to the desired level"

\section{References:}

[1]. Jill Williams (2005) Measuring Gender and Women's Empowerment Using Confirmatory Factor Analysis, IBS Working Paper,PACS-2005-01

[2]. Malhotra Anju, Sidney Ruth Schuler and Carol B'oender (2002) Measuring Women's Empowerment as a variable in International Development., World Bank Social Development Group.

[3]. World Economic Forum (2012) The Global Gender Gap Report-2012.

[4]. Human Rights Watch (2012) World Report-2012 ( Events of 2011)

[5]. Government of India (2011) Human Development Report -2011: Towards Social Inclusion, Oxford

[6]. Sunita Kishor and Kamla Gupta (2009) Gender Equality and Women Empowerment in India, National Family Health Survey (NFHS-3) India - 2005-06

[7]. Femida Handy and Meenaz Kassam (2004) "Women's Empowerment in Rural India”, Paper presented at the ISTR conference, Toronto, Canada, July 2004.

[8]. Marten Van Klaveren, Kea Tijdens, Melanie Hughie-Nilliams and Nuria Ramos Martin (2010) “An Overview of Women's work and employment in India", Working Paper 10-90, May 2010, AIAS.

[9]. Government of India (2010) Annual Report To The People on Employment, Ministry of Labour and Employment, New Delhi.

[10]. England Paula (2000) “Computing Women's Empowerment in Coutries of the North", pp.17-65, in Women's Empowerment and Demographic Processes: Moving Beyond Cairo, (Ed.) H.B. Presser and G.Sen, Oxford.

[11]. Kabeer Naila (1999) "Resources, Agency Achievements: Reflections on the Measurement of Women's Empowerment", Development and Change, 30: pp.435-464.

[12]. UNDP (2010) Human Development Report-2010

[13]. UNDP (2011) Human Development Report-2011

[14]. Government of India (2006) National Family Health Survey-2005-06, Ministry of Health and Family Welfare, New Delhi.

[15]. Beteta S Hanny (2006) "What is Missing in Measure of Women's Empowerment?", Journal of Human Development and Capabilities, Vol.7, No.2, pp.221-241.

[16]. Jean Dreze and Amartya Sen (2002) India: Development and Social Opportunity, Oxford

[17]. NSSO : Reports - No. 409 and 515 